\title{
Maternal drug histories and central nervous system anomalies
}

\author{
K A WINSHIP, D A CAHAL, J C P WEBER, AND J P GRIFFIN \\ Medicines Division, Department of Health and Social Security, London
}

SUMmaRY Prescription data for the three months before the last menstrual period and for the first trimester of pregnancy were obtained for 764 mothers whose children had a defect of the central nervous system and for an equal number of mothers of control babies born from the same doctors' practices. There was a statistically significant difference overall between the numbers of mothers who were prescribed drugs in the study and control groups during the trimester before the last menstrual period but no such difference was found for the first pregnancy trimester, nor was there a significant difference for any specific group of drugs. For a composite group of non-steroid anti-inflammatory drugs, salicylates, and sulphasalazine there was a significant difference for the trimester before the last menstrual period. There are arguments against such an artificial grouping, however, and when the individual drugs were considered the comparisons were no longer significant. The odds ratios for all medicines containing folic acid taken in the trimester before the last menstural period were considerably less than unity, in contrast with nearly all other comparisons. This supports a suggested protective effect against neural tube defects of folic acid supplements begun before the onset of pregnancy but the odds ratios of these comparisons were not statistically significant.

In 1977 Greenberg and others ${ }^{1}$ reported a study of the drug histories in the first trimester of pregnancy of 836 mothers of congenitally malformed children, 189 of whom had central nervous system defects, and an equal number of mothers of normal children. A positive association between the use of hormonal pregnancy tests and the subsequent birth of malformed children was found. Subsequent to this a further similar study on the mothers of congenitally malformed children and an equal number of mothers of normal children was undertaken by Cahal, Weatherall, and Adelstein (unpublished), covering the years 1976-80. Of 582 case-control pairs (183 central nervous sytem defects) studied, iron salts (with or without folic acid), anti-emetics, and antibiotics accounted for two thirds of all drugs prescribed in the first trimester. There was no evidence that they were teratogenic. There were significantly more prescriptions for bronchodilator drugs and for dextropropoxyphene in combination with paracetamol for the mothers of malformed children.

The present study was designed to cover notifications of central nervous system defects for one year, 1981. A total of 1078 notifications of actual or suspected defects were sent to the Committee on Safety of Medicines (CSM) by the Office of Population Censuses and Surveys (OPCS). These study children were paired with control children and analysis of maternal drug histories in the trimester (three calendar months) before the last menstrual period as well as in the first trimester of pregnancy was undertaken.

\section{Patients and methods}

The method of selection of patients and the study procedures were similar to those of the previous investigations. Each malformed (study) child was paired with a normal liveborn child without a congenital abnormality from the same medical practice. The control child was the nearest normal birth in the practice within three months after the birth of the study child, and if such a child was not available then the last normal child born within the practice before the birth of the study child was taken, provided that the interval did not exceed 12 months.

Method. Information on each study and control 
child and their mothers was obtained from the records of the family doctors, who were interviewed by part time medical officers (PTMOs) of the CSM. The children were not seen nor were their mothers interviewed. Data were collected on mother's age, family history, gestation period, outcome of the pregnancy, congenital abnormality in the study child, and drug prescriptions. Information on the drugs prescribed during the two study periods was obtained from the doctors' records only and is, therefore, not necessarily a complete record of drugs taken. It excluded hospital prescriptions, unless the doctors had a record of this, and also any 'over the counter' medicines which the mother might have taken. Gestation at any given date was calculated as the number of days or completed weeks from the first day of the last menstrual period. When the date of the last menstrual period was uncertain, obstetric and neonatal information was used to determine a probable date. This was done before analysing the results. The types of drug prescribed were recorded and where a drug had been prescribed more than once in either trimester it was noted as a single prescription in the appropriate trimester. Many of the medicines prescribed contained more than one active constituent. These constituents were analysed in terms of their therapeutic groups and may, therefore, be shown more than once in the analysis. In this study the risks of exposure to specific groups of drugs were calculated according to the method of Mantel and Haenszel ${ }^{2}$ for paired comparisons and then $95 \%$ confidence limits were estimated by the method of Breslow and Day. ${ }^{3}$

\section{Results}

Of the 1078 notifications of a central nervous system

Table 1 Reasons for rejection of notifications of congenital malformations

\begin{tabular}{lr} 
No malformation found on follow up & 102 \\
Patient, records, or family doctor untraceable & 51 \\
Family doctor unable to cooperate & 30 \\
No control child available & 17 \\
No PTMO available for follow up & 11 \\
Follow up incomplete at end of study, May 1982 & 87 \\
Trisomies and genetically transmitted conditions & 5 \\
Other reasons & 11 \\
Total & 314 \\
\hline
\end{tabular}

defect $314(29 \%)$ could not be accepted for the investigation: the reasons are given in Table 1 . One hundred and two notified births turned out to have no malformation due to misnotification related to administrative errors in linking the birth notification with the name and address of mother and doctor. (OPCS have since undertaken a study to see where the errors occur and how health authorities can overcome them.) Eighty seven $(8 \%)$ notifications were not included in the study because reports from PTMOs had not been completed by the time the enquiry ended. Nevertheless, the notifications received covered the whole of 1981 . The total number of children successfully paired with a control was 764. A total of $483(63 \%)$ of the 764 affected children were liveborn, of whom 271 survived the neonatal period. Two hundred and seventy two $(35.6 \%)$ were stillborn and in nine the outcome was not known.

Maternal age. The mean age of mothers of malformed babies was 25.9 years (range 15 to 49 ) and of control mothers $26 \cdot 6$ years ( 17 to 44$)$ at the child's birth. The overall difference between the means is not statistically significant but the age frequency distribution in five year subgroups as given in Table 2 shows a preponderance of women aged 15 to 19 years in the study group $(10 \%$ compared with $5 \cdot 7 \%)$. This difference is significant $(\mathrm{P}=0 \cdot 002)$.

Family history. Of the 764 case control pairs, 80 $(10.5 \%)$ case and $27(3.5 \%)$ control families had a history of congenital malformations either in siblings or in close relatives (grandparents, parents, uncles, aunts, and first cousins). Forty seven of the 80 $(59 \%)$ case families had a history of a central nervous system defect in relatives, in comparison with six of the $27(22 \%)$ control families; this is statistically significant as expected $(\mathrm{P}<0 \cdot 0001)$. There was consanguinity between parents in 11 of 536 case and five of 595 control families for whom there was information on this point.

Type of abnormality. Distribution of the types of central nervous system defect is shown in Table 3. Ninety six of the 764 affected infants were also reported to have abnormalities in other systems.

Drug prescribing before and during pregnancy. Two

Table 2 Number of mothers, in five year groups

\begin{tabular}{llllllll}
\hline & $15-19$ yrs & $20-24$ yrs & $25-29$ yrs & $30-34$ yrs & $35-39$ yrs & $40-44$ yrs & $45-59$ yrs \\
\hline Study mothers & 77 & 258 & 245 & 136 & 40 & 3 & 3 \\
Control mothers & 43 & 230 & 273 & 160 & 45 & 5 & 0 \\
\hline
\end{tabular}


Table 3 Distribution of central nervous system (CNS) defects among study children*

\begin{tabular}{lrr}
\hline Malformation & \multicolumn{2}{c}{ Affected children } \\
\cline { 2 - 3 } & $N o$ & $(\%)$ \\
\hline Anencephaly only & 143 & $(18 \cdot 7)$ \\
Hydrocephaly only $\dagger$ & 65 & $(8 \cdot 5)$ \\
Microcephaly only & 9 & $(1 \cdot 2)$ \\
Spina bifida only & 184 & $(24 \cdot 1)$ \\
Spina bifida with hydrocephaly & 215 & $(28 \cdot 1)$ \\
Anencephaly with spina bifida & 19 & $(2 \cdot 5)$ \\
Other CNS defects. single or multiple & & \\
$\quad$ specified and unspecified & 33 & $(4 \cdot 3)$ \\
CNS defects with malformations in & & $(12 \cdot 6)$ \\
$\quad$ other systems & 96 & \\
Total & 764 & 100 \\
\hline
\end{tabular}

*Mutually exclusive categories.

† Excludes sex linked cases

hundred and sixty four (35\%) study mothers and 226 $(30 \%)$ control mothers were prescribed 436 and 351 medicinal products respectively in the trimester before the last menstrual period. Four hundred and twenty three $(55 \%)$ study mothers and $440(58 \%)$ control mothers were prescribed 697 and 665 drugs respectively in the first trimester of pregnancy. Table 4 gives an analysis of the number of mothers for whom drugs were prescribed. In the trimester before the last menstrual period there is a significant difference between the drugs prescribed for the study and control groups of mothers, more of the study mothers having been prescribed drugs than the controls; the odds ratio is 1.29 with $95 \%$ confidence limits of 1.19 to 1.42 . In the first trimester of pregnancy no significant difference is found in drug prescribing between study and control mothers; the odds ratio being 0.88 with $95 \%$ confidence limits of 0.68 to $1 \cdot 14$.

Types of drugs prescribed. The main groups of drugs prescribed were iron salts, folic acid, antiemetics, antibiotics, and antihistamines. Other groups included central nervous system acting drugs, antifungal agents, oral contraceptives, infertility drugs, analgesics, and anticonvulsants. Tables 5 and 6 give details of these groups for each trimester.

Oral contraceptives prescribed in either trimester were not associated with a significant effect, nor were infertility drugs.

It was noticeable that the folic acid groups in both trimesters showed lower odds ratios than any of the others, most of which were in excess of unity. The numbers of patients in the trimester before the last menstrual period were unavoidably small and the $\chi_{c}^{2}$ values $\left(\chi^{2}\right.$ corrected for continuity) for the folic acid groups were not significant at the five per cent level. Six of seven control mothers had folic acid prescribed between 72 and five days before the last menstrual period, and for three the prescription was repeated in the first pregnancy trimester. The reasons for prescribing in the trimester before the last menstrual period were given as routine prophylaxis in two, prevention of anaemia in one, treatment of anaemia in one, iron deficiency in one, and iron treatment after a previous pregnancy in one as the preparations prescribed contained iron and folic acid. The remaining control mother was on continuous treatment for folic acid deficiency. A single study mother had folic acid prescribed six weeks before the last menstrual period for routine treatment after a previous normal pregnancy by a different partner. The father of the study child had two siblings both with central nervous system anomalies. Folic acid was not prescribed in the first pregnancy trimester.

In the first trimester, five study and eight control mothers had a folic acid preparation prescribed within four weeks of the last menstrual period, possibly as a prophylactic measure against central nervous system defects. In none of these mothers was there a history of previous children with a central nervous system defect. Two of the control mothers were also prescribed folic acid in the trimester before the last menstrual period, one for folic acid deficiency and the other as a prophylactic measure. Forty study mothers and 50 control mothers were prescribed folic acid between four and eight weeks from the last menstrual period, and 201

Table 4 Number of mother pairs prescribed drugs in the trimester before the last menstrual period and the first trimester

\begin{tabular}{lllllll}
\hline Trimester & $\begin{array}{l}\text { Study mother } \\
\text { only }\end{array}$ & $\begin{array}{l}\text { Control mother } \\
\text { only }\end{array}$ & Both mothers & $\begin{array}{l}\text { Neither } \\
\text { mother }\end{array}$ & Total & Odds ratio \\
\hline $\begin{array}{l}\text { Trimester before last } \\
\text { menstrual period }\end{array}$ & 170 & 132 & 94 & 368 & 764 & $1.29 \ddagger$ \\
$\begin{array}{l}\text { First trimester } \\
\text { Trim }\end{array}$ & 125 & 142 & 298 & 199 & 764 & 0.88 \\
\hline
\end{tabular}

* $\chi_{c}^{2}=\chi^{2}$ with continuity correction.

+ Critical value of $\chi^{2}$ for significance at $5 \%$ with one degree of freedom $=3 \cdot 84$.

$\$ 95 \%$ confidence limits of $1 \cdot 19-1 \cdot 42, P<0 \cdot 02$. 
Table 5 Drugs prescribed for study and control mother pairs in the trimester before the last menstrual period

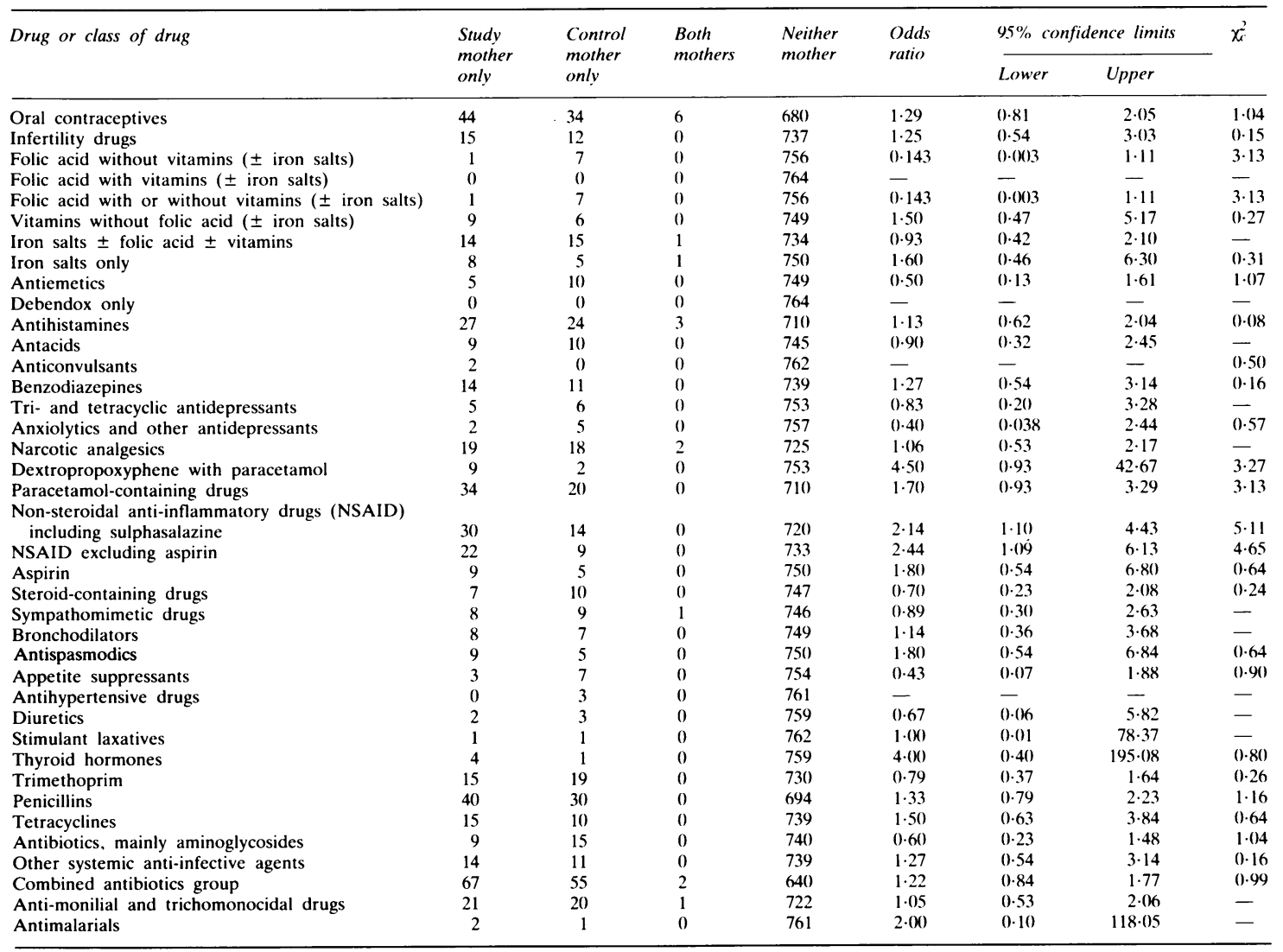

study and 216 control mothers between eight and 13 weeks, obviously some time after closure of the neural tube.

Four of 16 study mothers with a previously affected child were prescribed folic acid in the first trimester but none during the most sensitive period of organogenesis, (see Table 7). None of these study mothers was prescribed vitamins. One control mother had vitamins with folic acid at 11 weeks in the first trimester.

Only one of the nine study mothers prescribed vitamins without folic acid in the trimester before the last menstrual period was prescribed these because of a previous history of fetal malformations. The other eight mothers were prescribed vitamins (with or without iron salts), for menorrhagia in one and debility or pallor in the remainder. None of the six control mothers prescribed vitamins in the trimester before the last menstrual period was prescribed these as a prophylactic measure, the reasons being debility in five and abdominal discomfort in one.

In the present study iron-containing preparations were not significantly associated with the occurrence of central nervous system defects. Debendox was prescribed for 30 study and 29 control mothers in the first trimester.

Three of 764 study mothers had epilepsy, all three infants had spina bifida, and each mother had a different single anticonvulsant prescribed. None of the control mothers had suffered from epilepsy. One mother was prescribed sodium valproate in the first trimester only. Another mother had carbamazepine and the third phenytoin, each in both trimesters. One control mother was prescribed phenobarbitone for vomiting in early pregnancy.

Dextropropoxyphene with paracetamol was prescribed for nine study and two control mothers in the trimester before the last menstrual period, the odds ratio being $4 \cdot 50$, with $95 \%$ confidence limits of 
Table 6 Drugs prescribed for study and control mother pairs in the first trimester

\begin{tabular}{|c|c|c|c|c|c|c|c|c|}
\hline \multirow[t]{2}{*}{ Drug or class of drug } & \multirow{2}{*}{$\begin{array}{l}\text { Study } \\
\text { mother } \\
\text { only }\end{array}$} & \multirow{2}{*}{$\begin{array}{l}\text { Control } \\
\text { mother } \\
\text { only }\end{array}$} & \multirow{2}{*}{$\begin{array}{l}\text { Both } \\
\text { mothers }\end{array}$} & \multirow{2}{*}{$\begin{array}{l}\text { Neither } \\
\text { mother }\end{array}$} & \multirow{2}{*}{$\begin{array}{l}\text { odds } \\
\text { ratio }\end{array}$} & \multicolumn{2}{|c|}{$95 \%$ confidence limits } & \multirow[t]{2}{*}{$x^{2}$} \\
\hline & & & & & & Lower & Upper & \\
\hline Oral contraceptives & 5 & 2 & 1 & 756 & $2 \cdot 50$ & $0 \cdot 41$ & $26 \cdot 25$ & 0.57 \\
\hline Infertility drugs & 10 & 10 & 0 & 744 & $1 \cdot(0)$ & 0.37 & $2 \cdot 67$ & 0.05 \\
\hline Folic acid without vitamins $( \pm$ iron salts) & 73 & 94 & 146 & 451 & $0 \cdot 78$ & $0 \cdot 61$ & $1 \cdot() 2$ & $2 \cdot 39$ \\
\hline Folic acid with vitamins ( \pm iron salts) & 9 & 12 & 13 & 730 & 0.75 & 0.28 & 1.94 & $0 \cdot 19$ \\
\hline Folic acid with or without vitamins ( \pm iron salts) & $73^{*}$ & $98^{*}$ & 168 & 425 & 0.75 & 0.59 & 0.93 & $3 \cdot 37$ \\
\hline Vitamins without folic acid ( \pm iron salts) & 13 & 14 & 8 & 729 & 0.93 & $0 \cdot 40$ & $2 \cdot 13$ & - \\
\hline Iron salts \pm folic acid \pm vitamins & 87 & 110 & 194 & 373 & $(0.79$ & 0.62 & $1 \cdot 00$ & $2 \cdot 46$ \\
\hline Iron salts only & 17 & 19 & 11 & 717 & 0.89 & 0.44 & 1.89 & $0 \cdot 03$ \\
\hline Antiemetics & 60 & 55 & 5 & 644 & $1 \cdot 09$ & 0.74 & $1 \cdot 60$ & 0.14 \\
\hline Debendox only & 30 & 29 & 1 & 704 & $1 \cdot(0) 3$ & $0 \cdot 60$ & 1.79 & - \\
\hline Antihistamines & 25 & 21 & 1 & 717 & $1 \cdot 19$ & 0.63 & $2 \cdot 28$ & 0.20 \\
\hline Antacids & 28 & 22 & 1 & 713 & $1 \cdot 27$ & 0.66 & $2 \cdot 35$ & 0.50 \\
\hline Anticonvulsants & 3 & 1 & ) & 760 & $3 \cdot(0)$ & 0.24 & $157 \cdot 60$ & 0.25 \\
\hline Benzodiazepines & 14 & 14 & 0 & 736 & $1 \cdot(00$ & 0.44 & $2 \cdot 26$ & $0 \cdot 04$ \\
\hline Tri- and tetracyclic antidepressants & 8 & 7 & 0 & 749 & $1 \cdot 14$ & 0.36 & 3.68 & - \\
\hline Anxiolytics and other antidepressants & 0 & 2 & 0 & 762 & - & - & - & $0 \cdot 50$ \\
\hline Narcotic analgesics & 21 & 14 & 0 & 729 & $1 \cdot 50$ & 0.72 & $3 \cdot 21$ & $1 \cdot 03$ \\
\hline Dextropropoxyphene with paracetamol & 3 & 4 & 0 & 757 & 0.75 & $0 \cdot 11$ & $4 \cdot 43$ & - \\
\hline Paracetamol-containing drugs & 21 & 20 & 2 & 721 & $1 \cdot 05$ & 0.53 & $2 \cdot(1) 6$ & - \\
\hline \multicolumn{9}{|l|}{ Non-steroidal anti-inflammatory drugs (NSAID) } \\
\hline including sulphasalazine & 15 & 9 & 1 & 739 & $1 \cdot 67$ & $0 \cdot 67$ & $4 \cdot 27$ & $1 \cdot(04$ \\
\hline NSAID excluding aspirin & 7 & 6 & 1 & 750 & $1 \cdot 17$ & $0 \cdot 33$ & $4 \cdot 27$ & - \\
\hline Aspirin & 8 & 3 & 0 & 753 & $2 \cdot 67$ & $0 \cdot 64$ & $15 \cdot 72$ & 1.45 \\
\hline Steroid-containing drugs & 7 & 5 & 1 & 751 & $1 \cdot 40$ & $0 \cdot 38$ & $5 \cdot 66$ & 0.08 \\
\hline Sympathomimetic drugs & 5 & 6 & () & 753 & $0 \cdot 83$ & $0 \cdot 20$ & $3 \cdot 28$ & - \\
\hline Bronchodilators & 8 & 4 & 0 & 752 & $2 \cdot(0)$ & 0.54 & $9 \cdot 18$ & 0.75 \\
\hline Antispasomodics & 32 & 35 & 4 & 693 & 0.91 & 0.54 & $1 \cdot 56$ & $0 \cdot 06$ \\
\hline Appetite suppressants & 1 & 1 & 0 & 762 & $1 \cdot(0)$ & $0 \cdot(01$ & $78 \cdot 37$ & - \\
\hline Antihypertensive drugs & 1 & 3 & 0 & 760 & $0 \cdot 33$ & 0.006 & 4.15 & 0.25 \\
\hline Diuretics & 2 & 1 & 0 & 761 & $2 \cdot(0)$ & $0 \cdot 10$ & $118 \cdot 05$ & - \\
\hline Stimulant laxatives & 8 & 4 & 1 & 751 & $2 \cdot(0)$ & 0.54 & $9 \cdot 18$ & 0.75 \\
\hline Thyroid hormones & 4 & 1 & 0 & 759 & $4 \cdot(0)$ & $0 \cdot 40$ & $195 \cdot(08$ & $0 \cdot 80$ \\
\hline Trimethoprim & 6 & 8 & 0 & 750 & 0.75 & $0 \cdot 21$ & $2 \cdot 51$ & 0.07 \\
\hline Penicillins & 38 & 51 & () & 675 & 0.75 & 0.46 & $1 \cdot 21$ & 1.62 \\
\hline Tetracyclines & 5 & 3 & 0 & 756 & 1.67 & $0 \cdot 32$ & $10 \cdot 79$ & $0 \cdot 13$ \\
\hline Antibiotics, mainly aminoglycosides & 15 & 10 & 2 & 737 & $1 \cdot 50$ & $0 \cdot 63$ & $3 \cdot 84$ & 0.64 \\
\hline Other systemic anti-infective agents & 10) & 4 & 0 & 750 & $2 \cdot 50$ & 0.72 & $10 \cdot 75$ & 1.79 \\
\hline Combined antibiotics group & 58 & 63 & 4 & 639 & 0.92 & 0.63 & $1 \cdot 34$ & $0 \cdot 13$ \\
\hline Anti-monilial and trichomonocidal drugs & 17 & 13 & 1 & 733 & $1 \cdot 31$ & 0.58 & 2.91 & $0 \cdot 30$ \\
\hline Antimalarials & 1 & 0 & 0 & 763 & $1 \cdot(0)$ & - & - & - \\
\hline
\end{tabular}

*These figures are not a summation of the two previous groups because some mothers had been prescribed folic acid-containing medicines with a vitamin and without a vitamin in the same trimester.

Table 7 Details of prescribing for 17 mothers with one or more previous children with a central nervous system anomaly

\begin{tabular}{|c|c|}
\hline Trimester & Drugs prescribed \\
\hline $\begin{array}{l}16 \text { study mothers* } \\
\text { Trimester before the } \\
\text { last menstrual period } \\
\text { First trimester }\end{array}$ & $\begin{array}{l}13 \text { no drugs } \\
2 \text { insulin (mothers diabetic) } \\
1 \text { Distalgesic. Synflex. Indocid, and Asilone } \\
9 \text { no drugs } \\
2 \text { insulin (see above) and Pregaday at over } 3 \text { weeks } \\
\text { (exact date not known) } \\
\text { and one Ferrograd Folic at } 10 \text { weeks } \\
1 \text { Fefol at over } 9 \text { weeks and Distaclor at } 12 \text { weeks } \\
1 \text { Pregaday at } 8 \text { weeks } \\
1 \text { Slow-Fe at } 7 \text { weeks } \\
1 \text { Debendox and Canestan vaginal tablets } \\
1 \text { Debendox, Dorbanex, and Otosporin (the } \\
\text { mother who had } 4 \text { drugs prescribed, see above) }\end{array}$ \\
\hline $\begin{array}{l}1 \text { control mother } \\
\text { Trimester before the } \\
\text { last menstrual period } \\
\text { First trimester }\end{array}$ & Fefol Vit at 11 weeks \\
\hline
\end{tabular}

*14 study families had a similar neural tube defect in a previous sibling. 14 of the 16 mothers had one and two had two previously affected children.
0.93 to 42.67 which is not quite statistically significant.

On the basis that aspirin, non-steroidal antiinflammatory drugs, and sulphasalazine (an aminosalicylate) all have possibly similar anti-inflammatory activity, we produced a composite group of these drugs and found that they had been prescribed significantly more frequently for the study group of mothers during the trimester before the last menstrual period (odds ratio $2 \cdot 14,95 \%$ confidence limits $1 \cdot 10$ to $4 \cdot 43, \mathrm{P}=0 \cdot 02)$. There are, however, arguments against combining these drugs in a single group. For instance, sulphasalazine is used to treat ulcerative colitis which might itself have a possible effect on the occurrence of fetal anomalies, although we are unaware of any. When these drug groups were evaluated separately, there were no significant differences in the odds ratios. In the first trimester no significant difference was shown for this compo- 
site group, the odds ratio being $1 \cdot 67$, with $95 \%$ confidence limits of 0.67 to $4 \cdot 27$.

Antibiotics, benzodiazepines, and tri- and tetracyclic antidepressants did not show any association with central nervous system defects when given in either trimester; neither did sympathomimetic drugs, bronchodilators, antispasmodics, etc.

\section{Discussion}

The mothers studied in this survey were not matched for age or for social class, and it would be presumptuous to suggest that every other possible confounding factor had been eliminated. Golding and colleagues ${ }^{4}$ comment that it is not technically possible to match for general practitioner as well as to match for social class and other factors in the mother which may be relevant. ${ }^{5}$ The mothers themselves were not interviewed to see what other drugs and medication they took during the two periods studied.

Some degree of inequality in the five year age subgroups has already been mentioned. Older women are said to have a greater tendency to give birth to malformed babies. ${ }^{5}$ There is also, however, a tendency for the rate to be increased for first births in the lower maternal age range in Britain. ${ }^{5}$ Parity is also to some extent linked to age as regards this effect and may be an additional confounding factor. The design of this study was similar to that of the two studies already mentioned; neither age nor parity was a criterion for matching because of the method of selecting controls in which the infant rather than the mother was the determinant of inclusion in the control group. It is intended to carry out a further study in which an attempt to control for these factors as far as possible will be made. The results of this study must, therefore, be regarded to some extent as preliminary.

The proportion of stillbirths is lower than would be expected; this is largely due to the increasing numbers of central nervous system defects which are diagnosed antenatally and followed by termination of pregnancy. Weatherall ${ }^{6}$ showed a steady increase over the past ten years in the number of legal abortions carried out for medical reasons. In 1974 there were 2452 births and 34 terminations for central nervous system defects, in 1978 there were 1757 births and 194 terminations, and in 1981 the births notified totalled 1078 and there were 445 terminations. The rate of this decline in stillbirths seems to have accelerated but cannot be accounted for only by terminations. Central nervous system defects also seem to have declined in Northern Ireland,${ }^{7}$ the United States, ${ }^{89}$ and Australia, ${ }^{10} 11$ though the reduction has been less striking in these countries than in England and Wales.

Nora and colleagues ${ }^{12}$ found an excess of children with central nervous system defects after maternal hormonal exposure, but our study did not show this. Three cohort studies (Robinson, ${ }^{13}$ Royal College of General Practitioners Oral Contraception Study, ${ }^{14}$ and Vessey and co-workers ${ }^{15}$ ) also provided no evidence of a significant association between oral contraceptive use and central nervous system defects, but the numbers of cases were small in these studies as in our present one. More recently, Cuckle and $\mathrm{Wald}^{16}$ were unable to provide any further positive evidence on the oral contraceptives issue, adding that if a risk exists it can only be small. Infertility drugs were not associated with central nervous system malformations in our study, nor were they in the Collaborative Perinatal Project analysed by Heinonen et al. ${ }^{17}$

Closure of the neural tube is usually considered complete by the fourth week of pregnancy so that if folic acid is to have a prophylactic effect against neural tube defects it is clearly necessary for it to have been taken before and immediately after conception. Our findings on folic acid, though not statistically significant, are not incompatible with those of recent studies ${ }^{18}{ }^{19}$ which show that folic acid supplementation before and during early pregnancy seems to reduce the risk of recurrence of neural tube defects in mothers who already have an affected child.

Mulinare and colleagues ${ }^{20}$ looked at the vitamin intake either preconceptually or during the first trimester, or both, among women who had offspring with a neural tube defect, their controls being women who had offspring with other malformations. A statistically significant protective effect of vitamin usage was shown for white mothers. The authors suggest that vitamins are usually begun in the latter part of the first trimester when their use could be in the stabilisation of cellular integrity of the neuropore after the 26th day of embryogenesis, with possible prevention of overdistension and subsequent rupture of the neuropore.

The above study did not, however, look at the role of folic acid separately from other vitamins and whether their influence was in either or both three month periods. Our analysis of vitamin prescribing, excluding folic acid, did not show any significance in either trimester.

Nelson and Forfar ${ }^{21}$ found that during the first 56 days of pregnancy a significantly high proportion of mothers of infants with major abnormalities took iron-containing preparations compared with control mothers, but no positive association was found in our study for either trimester. 
Milkovich and van den Berg ${ }^{22}$ in a large prospective trial were not able to show that either Debendox or other antinauseant drugs were associated with teratogenicity. Smithells and Sheppard ${ }^{23}$ found no increase in congenital malformations in 2298 patients taking Debendox during pregnancy when compared with a control population. This lack of adverse effect is supported by analysis of the Collaborative Perinatal Project data by Shapiro and others ${ }^{24}$ for doxylamine and dicyclomine separately. No increase in congenital malformations was observed in about 900 exposed offspring. An investigation undertaken in Northern Ireland ${ }^{25}$ also showed no relation between congenital malformations and the use of Debendox. On the other hand there are anecdotal reports ${ }^{26}{ }^{27}$ of small numbers of malformations associated with its use. Golding and others ${ }^{4}$ advised caution in prescribing, because there was a significant excess of women who had been prescribed Debendox in early pregnancy in their recent study of cleft lip and palate, but they did not regard this as conclusive evidence of a teratogenic effect. Neither in our study nor in the Boston Collaborative Study ${ }^{17}$ was there any evidence of an association of central nervous system defects with use of antihistamines.

Azad Khan and Truelove ${ }^{28}$ showed that sulphasalazine and its metabolites reach the fetus in concentrations not greatly different from those in maternal serum. There is, therefore, a theoretical risk that the fetus might be affected as maintenance treatment for ulcerative colitis is recommended throughout pregnancy; it seems to have been taken in this way by the four mothers in our study group. In 1983 an anecdotal report ${ }^{29}$ described cardiovascular and genito-urinary abnormalities in three infants of two mothers who had taken sulphasalazine during their pregnancies; the histories suggest that treatment had begun before their pregnancies. Another anecdotal report $^{30}$ recorded hydrocephalus and oral cleft in the infant of a mother who had had sulphasalazine for ulcerative colitis before and throughout pregnancy. These reports cast some doubt on the complete safety of sulphasalazine for the developing fetus. Although four of our study mothers were prescribed sulphasalazine, we are reluctant to suggest any definite association with fetal abnormalities and we were unable to find any relevant experimental data.

Aspirin alone did not show a significant effect in this study. Slone and others ${ }^{31}$ reporting on the Collaborative Perinatal Project on a cohort of 50282 pregnant women of whom $64 \%$ took aspirin at some time during the pregnancy, concluded that the study gave no evidence that aspirin ingestion during pregnancy is associated with an increase in malformations. They also added that the data were so extensive that it was unlikely that any substantial teratogenic effect would have been missed. Anecdotal reports have implicated aspirin as a possible teratogen but there are also many instances of women taking large doses of aspirin throughout pregnancy without ill effects on the baby. Most of the evidence on aspirin suggests that it is not teratogenic if used in normal dosage.

The weakly positive finding for the antibiotics, benzodiazepines, and tri- and tetracyclic antidepressants for study mothers in the first trimester in the earlier report ${ }^{1}$ could not be found in this present study. Two prescriptions only were given for barbiturates, and hormone pregnancy tests were not prescribed for any mother in our study. In the unpublished study by Cahal, Weatherall, and Adelstein significantly more bronchodilator drugs were prescribed to mothers of malformed children, however our study was not able to show this association. Many other groups of drugs were analysed but a positive association was not shown, (see Tables 5 and 6). Our findings for dextropropoxyphene in combination with paracetamol in the trimester before the last menstrual period, thyroid hormones in both trimesters, and anticonvulsants in the first trimester, though slightly suggestive, were not statistically significant.

We were impressed by the fact that the crude odds ratio was in excess of unity in the large majority of the comparisons, whereas for the preparations containing folic acid they were of the order $\mathbf{0} \cdot 1$, considerably lower than those for any other group. None of the ratios in excess of unity was statistically significant (with the exception of our combined non-steroid anti-inflammatory drug group in the trimester before the last menstrual period.) Although the confidence intervals for the folic acid preparations just reached unity, the low odds ratios could be regarded as possibly compatible with a protective effect of folic acid against neural tube defects, about which further data should be obtained from prospective studies.

The imperfections in study design to which we have referred are, we think, unlikely to have led to any major systematic bias. Our finding of a seemingly significant effect with regard to antiinflammatory drugs must be interpreted with considerable caution in view of the lack of any confirmatory experimental or clinical data, of the arguments against the aggregation of non-steroid anti-inflammatory drugs, salicylates, and sulphasalazine on which the validity of the significance depends, and of the absence of statistical significance when each member of the group is considered separately. Apart from this, we were unable to 
obtain any evidence of a teratogenic effect for any of the considerable number of drug groups examined.

We thank the staff of the health authorities, all participating doctors and the CSM part-time medical officers for their assistance in collecting data; Dr M R Alderson, Chief Medical Statistician, and the staff of the Medical Statistics Unit (OPCS) for processing the notifications and calculating the confidence limits of the odds ratios; and Professor Sir Abraham Goldberg, Professors Martin Vessey and Bryan Hibbard for their constructive comments and guidance. We acknowledge untiring technical assistance from the computer staff, especially Mr D Beaumont, and we thank Dr C Twomey for checking data and Miss L Whyte for typing the manuscript and tables.

Dr D A Cahal died in 1983.

\section{References}

${ }^{1}$ Greenberg C, Inman WHW, Weatherall JAC, Aldestein AM, Haskey JC. Maternal drug histories and congenital abnormalities. Br Med J 1977;ii:853-6.

2 Mantel N. Haenszel W. Statistical aspects of the analysis of data from retrospective studies of disease. Journal of the National Cancer Institute 1959;22:719-48.

${ }^{3}$ Breslow NE, Day NE. Statistical methods in cancer research. Vol 1. Analysis of case-control studies. Lyon: IARC Scientific Publications, 1980: 165-6.

4 Golding J, Vivian S, Baldwin JA. Maternal antinauseants and clefts of lip and palate. Hum Toxicol 1983;2:63-73.

${ }^{5}$ Leck I. Causation of neural tube defects: clues from epidemiology. Br Med Bull 1974;30:158-63.

${ }^{6}$ Weatherall JAC. A review of some effects of recent medical practices in reducing the numbers of children born with congenital abnormalities. Health Trends. London: HMSO, 1982;14:85-8.

7 Nevin NC. Neural tube defects. Lancet 1981;ii:1290-1.

${ }^{8}$ Stein SC, Feldman JG, Friedlander M. Klein RJ. Is myelomeningocele a disappearing disease? Pediatrics 1982;69:511-4.

9 Windham GC. Edmonds LD. Current trends in the incidence of neural tube defects. Pediatrics 1982;70:333-7.

10 Field B, Kerr C, Mathers CD. Incidence of neural tube defects. Dev Med Child Neurol 1982;24:861-2.

1 Danks DM. Halliday JL. Incidence of neural tube defects in Victoria, Australia. Lancet 1983;i:65.

12 Nora JJ, Nora AH, Blu J, et al. Exogenous progestogen and estrogen implicated in birth defects. JAMA 1978;240:837-43.

13 Robinson SC. Pregnancy outcome following oral contraceptives. Am J Obstet Gynecol 1971;109:354-8.

14 Royal College of General Practitioners Oral Contraception Study. The outcome of pregnancy in former oral contraceptive users. Br J Obstet Gynaecol 1976;83:608-16.

15 Vessey M, Meisler L, Flavel R, Yeates D. Outcome of pregnancy in women using different methods of contraception. Br J Obstet Gynaecol 1979;86:548-56.

${ }^{16}$ Cuckle HS, Wald NJ. Evidence against oral contraceptives as a cause of neural tube defects. Br J Obstet Gynaecol 1982;89: 547-9.

17 Heinonen OP, Slone D, Shapiro S, eds. Birth defects and drugs in pregnancy. Littleton: Publishing Sciences Group, 1977.

${ }^{18}$ Smithells RW, Sheppard S, Schorah CJ, et al. Apparent prevention of neural tube defects by periconceptional vitamin supplementation. Arch Dis Child 1981:56:911-8.

19 Smithells RW, Nevin NC, Seller MJ, et al. Further experience of vitamin supplementation for prevention of neural tube defect recurrences. Lancet 1983;i:1027-31.

${ }^{20}$ Mulinare J, Cordero JF, Erickson JD. Vitamin use and the occurrence of neural tube defects (NTD's). Teratology 1981;23:54A.
${ }^{21}$ Nelson MM, Forfar JO. Associations between drugs administered during pregnancy and congenital abnormalities of the fetus. Br Med J 1971;i:523-7.

22 Milkovich L, van den Berg BJ. An evaluation of the teratogenicity of certain antinauseant drugs. Am J Obstet Gynecol 1976;2:244-8.

${ }^{23}$ Smithells RW, Sheppard S. Teratogenicity testing in humans: a method demonstrating safety of Bendectin. Teratology 1978; 17:31-6.

${ }^{24}$ Shapiro S, Heinonen OP, Siskind V, Kaufman DW, Monson RR, Slone D. Antenatal exposure to doxylamine succinate and dicyclomine hydrochloride (Bendectin) in relation to congenital malformations, perinatal mortality rate, birth weight. and intelligence quotient score. Am J Obstet Gynecol 1977:128:480-5.

25 Harron DWG, Griffiths K, Shanks RG. Debendox and congenital malformations in Northern Ireland. $\mathrm{Br}$ Med $\mathrm{J}$ 1980;ii:1379-81.

26 Patterson DC. Congenital deformities associated with Bendectin. Can Med Assoc J 1977:116:1348.

27 Donnai D, Harris R. Unusual fetal malformations after antiemetics in early pregnancy. Br Med J 1978;i:691-2.

28 Azad Khan AK. Truelove SC. Placental and mammary transfer of sulphasalazine. Br Med J 1979;ii: 1553 .

29 Newman NM, Correy JF. Possible teratogenicity of sulphasalazine. Med J Aust 1983;1:528-9.

30) Craxi A, Pagliarello F. Possible embryotoxicity of sulfasalazine. Arch Intern Med 1980;140:1674.

${ }^{31}$ Slone D, Siskind V, Heinonen OP, Monson RR, Kaufman DW, Shapiro S. Aspirin and congenital malformations. Lancet 1976:i: $1373-5$.

Correspondence to Dr K Winship. Department of Health and Social Security, Market Towers, 1 Nine Elms Lane, London SW8 $5 N Q$.

Received 5 July 1984

\section{Commentary}

\section{R W SMITHELLS}

\section{Department of Paediatrics and Child Health, University of Leeds}

Reports of an apparent protective effect of folic acid, with ${ }^{1}$ or without $^{2}$ other vitamins, against recurrence of neural tube defects have led to a lively debate $^{3-5}$ and to the initiation of further intervention studies. These further studies are likely to take many years to complete and may be no easier to interpret at the end of the day than those already published.

Meanwhile, indirect illumination of this important area of preventive paediatrics is welcome. Winship et al have extended a study originally designed to examine the possible teratogenicity of drugs and have found a remarkable negative association between folic acid and central nervous system anomalies, particularly with folic acid prescribed in the trimester before the last menstrual period. This 